\title{
ASSESSING THE EFFECTIVENESS OF VOLUNTARY SOLID WASTE REDUCTION POLICIES: METHODOLOGY AND A FLEMISH CASE STUDY
}

\author{
Simon De Jaeger ${ }^{\mathrm{a}^{*}}$ and Johan Eyckmans ${ }^{\mathrm{a}, \mathrm{b}}$ \\ ${ }^{a}$ EHSAL - European University College Brussels, Stormstraat 2, Belgium. \\ ${ }^{b}$ Affiliated researcher at K.U.Leuven, Centrum voor Economische Studiën, Belgium.
}

This version March 1, 2007

\begin{abstract}
The purpose of this paper is to illustrate the use of statistical techniques to evaluate the effectiveness of voluntary policy instruments for waste management. The voluntary character of these instruments implies that latent characteristics, unobserved by the analyst, might influence the participation decision and might lead to biased estimates of the effectiveness of the policy instrument if standard techniques are used. We propose an extension of the Difference-inDifferences estimator to evaluate the effectiveness of voluntary policy instruments. We illustrate the technique by estimating the effectiveness of voluntary cooperation agreements between the Flemish environmental administration and individual municipalities. We focus on agreements which aim at curbing residential solid waste. Using a dataset covering all 308 Flemish municipalities for the period 2000 - 2005, our results indicate that municipalities subscribing to the agreement reduced their waste level by less than what could be expected on the basis of their own performance prior to subscription and the performance of the non-subscribers. This result might be explained by rising marginal cost of extra residential solid waste reduction policies. In addition, there are indications that subscribing municipalities refrain from additional reduction efforts once the target waste level of the program is achieved.
\end{abstract}

\section{Keywords}

Residential solid waste, difference-in-differences, voluntary agreements, municipalities, endogeneity bias.

\footnotetext{
* corresponding author, email: simon.dejaeger@ehsal.be, telephone number: +32(0)2 6098255
} 


\section{Introduction}

During the last two decades, voluntary approaches to reduce pollution have become popular environmental policy instruments. The report, Voluntary approaches for environmental policy by the Organization for Economic Cooperation and Development (OECD, 2003) gives a typology of different types of voluntary approaches and includes many case studies of such programs in OECD member states. Examples include the $33 / 50$ program to curb the emissions of 17 high priority toxic chemicals in the US industry (Khanna and Damon, 1999) or the voluntary agreements between industry federations and environmental authorities regarding energy efficiency in Denmark (Bjørner and Jensen, 2002).

Also in waste management, several examples can be quoted. For instance, garbage fees and curbside recycling programs in the US are voluntary in the sense that local municipalities can choose to adopt these waste management tools but are not forced by law to do so (Kinnaman and Fullerton, 2000). Another example can be found in the region of Flanders (a semiautonomous region in Belgium) where municipalities can subscribe to a voluntary agreement under which they can receive subsidies if they achieve pre-specified residential solid waste targets (De Jaeger et al., 2005). We will analyze the Flemish case study in detail in this paper to illustrate the use of a particular evaluation methodology (see later).

Several attempts have been undertaken to evaluate the effectiveness of voluntary programs. Theoretical analyses in the environmental economics literature are based on stylized models of polluters' behavior and are all rather skeptical about the effectiveness and economic efficiency of voluntary agreements. A general conclusion from this literature is that some kind of credible threat - like for instance the implementation of an emission tax if environmental targets are not achieved - is a necessary condition for a voluntary agreement to be effective (Segerson and Micelli, 1998 and OECD, 2003). Empirical studies of the effectiveness of voluntary approaches 
seem to confirm this theoretical result. For instance, the $33 / 50$ program on toxic chemicals and the Danish program on energy efficiency cited earlier, achieved additional environmental progress. However, the main motivations for participating in these programs seem to be positive reputation effects and fear of alternative mandatory regulation.

When assessing empirically the impact of a policy program on the behavior of some target group, one typically has to use non-experimental data, since experimental data are usually not available. It almost never happens that policies are tested a priori by selecting a random sample of target group members, exposing them to the policy, and afterwards comparing their environmental performance to the performance of a randomly selected control group. This type of experiment is often legally not permitted by the imperative of equal treatment or is deemed ethically unacceptable. The difficulty with non-experimental data for the evaluation of voluntary environmental programs is that one cannot just compare average performance of subscribers and non-subscribers. Since subscribers have self-selected into the program, assignment to treatment is probably non-random. In that case, standard statistical procedures to compare, for instance, average environmental performance, are no longer reliable tests for effectiveness of the voluntary policy program, see Shadish et al. (2002).

Fortunately, several methods for policy evaluation with non-experimental data have been developed, see Moffitt (1991) and Meyer (1995) for general introductions and Heckman at al. (1998b) and Blundell and Costa Dias (2000) for more technical reviews. Techniques such as difference-in-differences, matching, instrumental variables, and Heckman's two-stage estimator are commonly used methods for program evaluation. However, when assessing effectiveness of waste reduction policies these statistical methods are rarely used. In this paper we give an introduction to one of these techniques - the dynamic difference-in-differences estimator (or DiDiD) - and argue that it is a useful tool for assessing waste management policies. The main 
contribution of this paper is twofold. First, we show that existing dynamic DiD techniques can be extended to accommodate for more than one treatment group. Second, we apply this technique to a Flemish voluntary waste policy program to demonstrate its relevance for evaluating waste management policies.

The paper is organized as follows: section 2 introduces some policy evaluation terminology and in section 3 we discuss the ordinary difference-in-differences estimator. Section 4 describes the case study for Flanders including a brief description of the voluntary agreements between the Flemish environmental authorities and municipalities and an informal inspection of the data on residential solid waste in Flemish municipalities. In section 5 we present an intuitive as well as a formal derivation of the dynamic extension of the difference-in-differences estimator and we discuss regression results in section 6 . Section 7 concludes.

\section{Policy evaluation terminology}

\subsection{Outcome variables, treated and non-treated subjects}

First, we introduce some terminology regarding policy evaluation. In line with, for instance, Mickwitz (2003), we define the outcome variable as the ultimate policy target variable that the environmental authorities want to influence. For instance, this might be energy efficiency, measured as energy used per unit of production or, in case of waste management, the annual production of residential solid waste by households. The outcome variable is typically under the control of the actors or target group (the polluting firms or households) but can not be controlled directly by the environmental authorities. The authorities can only try to steer the target group's behavior indirectly by certain (combinations of) policy instruments like technology standards, emission limits, emission taxes, subsidies or different types of voluntary agreements between polluters and environmental authorities. We will focus on the last type of 
instrument and we will use interchangeably the terms treated subjects for participants and nontreated subjects or control group for non-participants in those voluntary programs.

\subsection{Endogeneity bias}

In voluntary environmental programs the participation decision is typically correlated with observable characteristics and with latent characteristics which are unobserved by the analyst. If such a correlation exists, assignment to treatment cannot be regarded as random and internal validity of standard treatment effect estimators might be violated, see Shadish et al. (2002). Estimating the effectiveness of the program by comparing the average performance of treated and non-treated subjects would yield an over- or underestimation of the real treatment effect depending on the sign of the correlation. This problem is commonly referred to as endogeneity bias.

Consider as an example an environmental authority that wants local municipalities (the target group in this case) to set up public information campaigns in order to limit the total amount of residential solid waste and to increase recycling rates. In order to stimulate the municipalities, the environmental authority provides subsidies for municipalities that achieve certain minimum recycling rates by a certain year. Assume the analyst has observations on which municipalities have entered the voluntary scheme and on the outcome variable, i.e. solid waste and recycling data, for all municipalities in the country. Given the voluntary nature of the program, municipalities self-select into the agreement depending on observed characteristics like past environmental policies, population size, degree of urbanization, state of municipal budget, etc. In addition, characteristics unobserved by the analyst might matter. For example, municipalities may be more prone to participate in the price-per-bag program because their residents are "green minded".

These background characteristics of program participants cause the superficial picture of the effectiveness of the program (for instance the comparison of average performance of treated and 
non-treated subjects) to be a blurred picture of the real treatment effect. Fortunately, several methods are available for correcting this blurred picture. Each of these methods can be regarded as a set of corrective lenses that can re-establish the internal validity of treatment effect estimators, provided particular identification assumptions are valid.

\section{Policy evaluation estimators}

\subsection{Difference-in-difference estimators}

A widely used approach in policy evaluation is the so-called difference-in-differences (DiD) estimator that compares average progress, i.e., the difference between the outcome variable after and before treatment, of participating subjects with that of non-participating subjects in the program. Obviously, to apply the DiD estimator, one needs observations on the outcome variable for at least one period before and one period after treatment. In the $\mathrm{DiD}$ approach, the treatment effect of a policy program is defined as the difference between the progress of the treated and the non-treated. Implicitly DiD assumes that treated subjects could have achieved the same progress as non-treated ones. Therefore, the real effectiveness of the policy program is reflected only in the additional effort made by participants. See Moffitt (1991) and Meyer (1995) for introductions to the DiD technique.

Just like any other estimator of policy effectiveness, the DiD technique requires a particular identification restriction. The identification restriction underlying the $\mathrm{DiD}$ methodology requires that the expected change in outcome, in the absence of treatment, is the same for the treated group as for the non-treated or control group. This is the so-called common trend assumption in ordinary DiD estimators, see for instance Blundell and Costa Diaz (2000), Meyer (1995) or Moffitt (1991) for a discussion on identification restrictions and DiD. If this identification restriction holds, the DiD methodology provides an internally valid estimate of the real treatment effect. Note that the identification restriction cannot be tested empirically since it 
refers to a counterfactual question: how would the treated group have behaved if they had not been treated?

Any violation of the common trend assumption would cause the DiD estimator to deliver a blurred picture of the real treatment effect. Possible violations of this identification restriction arise from characteristics that do not remain constant over time (i.e., characteristics which do not have the same influence on the outcome variable before and after treatment) and that have a different effect on treated and non-treated subjects. For instance, treated subjects might have exerted more effort in the past than subjects in the control group, so that achieving additional progress is more expensive to the treated.

We will come back to the discussion on the appropriateness of the common trend identification restriction in our case study on Flemish waste management policy below.

\subsection{Other evaluation estimators}

In the statistics and economics literature, several other methods have been developed to account for endogeneity problems when dealing with non-experimental data. Some commonly used alternative techniques are, amongst others, matching, Heckman's two-step estimator and Instrumental Variables estimators. Our focus in this paper is on DiD methodology (and its extensions) and we will therefore not discuss these alternative techniques in detail. However, we provide the interested reader some references and applications of these techniques to the evaluation of voluntary policy programs.

Matching is basically a method for constructing the control group when dealing with nonexperimental data. For each treated unit a comparable non-treated control unit is selected based on one, or on a set of, background characteristic(s). The matching method is currently a popular tool in social sciences and the technique is often combined with another method like differencein-difference estimators. See Heckman et al. (1998a) for details on the matching technique. 
Another popular tool in empirical research is Heckman's two-step estimator. The intuition behind this method is to distinguish explicitly between the decision regarding participation and the decision on the level of the outcome variable (Heckman, 1979). Heckman's two-stage estimator is widely used in econometric analyses of labor market policies, for instance, the impact of voluntary training programs for the unemployed on their probability to find a job or to estimate the wage elasticity of female labor supply.

If one has reasons to believe that the participation decision in a voluntary policy program is correlated with unobserved characteristics that also influence the outcome variable, and if observations on both participating and non-participating subjects are available, an Instrumental Variables approach can be used to correct for possible endogenous bias. ${ }^{1}$ Khanna and Damon (1999) provide an application of this technique to evaluate the effectiveness of the EPA's voluntary $33 / 50$ program on the reduction of toxic chemicals. Millock and Nauges (2006) use a similar procedure to evaluate the effectiveness of a combined emission tax and emission abatement subsidy program in France. Also Kinnaman and Fullerton (2000) apply this technique to estimate the impact of garbage fees and curbside recycling programs on residential solid waste and recycling amounts in the United States.

\section{Case study of Flanders}

\subsection{Voluntary agreements between environmental authorities and municipalities}

Under the Belgian constitutional system, the three regions - the Flemish Region with 6 million inhabitants, the Brussels-Capital Region with one million inhabitants, and the Walloon Region with 3.4 million inhabitants - enjoy considerable autonomy regarding environmental policy. The Public Waste Agency of Flanders (OVAM) is responsible for preparing and implementing the regional waste management policy in Flanders. In practice, however, local municipalities

\footnotetext{
${ }^{1}$ A thorough introduction to this technique can be found in Verbeek (2000).
} 
and city councils organize the collection and disposal of household waste. They decide on the practical details of the collection system such as frequency of collection, payment schemes like head tax, pay-per-bag, etc., recycling strategies and disposal of collected waste materials. The policies chosen by these local authorities should be in line with the principles of the higher level environmental authorities.

Against this legal background, the Flemish regional government has set up a system of voluntary agreements, the so-called "Samenwerkingsovereenkomst" (literally translated: cooperation agreements) with the local municipalities and provinces in order to assist them to implement the regional environmental and waste management strategy. Municipalities can subscribe to the agreement on a voluntary basis. By subscribing, the municipality commits itself to carry out particular tasks and meet well defined goals. In exchange, the local authority receives financial support from the Flemish environmental authorities. The cooperation agreement consists of eight different clusters each of which covering a particular environmental policy domain (i.e., (1) water, (2) waste, (3) energy, (4) mobility, (5) nature, (6) pollution, (7) target groups and (8) policy instruments) and three ambition levels (i.e., (1) level one: entry, (2) level two: advanced and (3) level three: ambitious level). Each participating municipality or province is to a large extent free to select the clusters and corresponding ambition levels at which it wants to subscribe. It should be noted that the cooperation agreement had a predecessor called the environmental covenants which were in place from 1992 to 2001.

In this paper we focus on the agreements with municipalities and on the residential solid waste cluster for the period $2002-2004$. The strategic goal for this group is to reduce the production of residential solid waste (Ministerie van de Vlaamse Gemeenschap, 2001, p.22-23) and it

\footnotetext{
${ }^{2}$ See http://www.samenwerkingsovereenkomst.be (in Dutch only) for the details of the agreements. An English PowerPoint presentation is available at : http://www.mina.be/uploads/ppt_cooperation_agreement.zip.
} 
specifies a detailed time frame and quantitative policy goals. Residential solid waste includes (1) all residual waste presented by households at the curbside, (2) bulky household refuse, and (3) municipal waste ${ }^{3}$. The first part, residual household waste, is the fraction of total household waste remaining after recycling ${ }^{4}$. In 2004, this fraction represented about $75 \%$ of all Flemish residential solid waste (OVAM, 2005). The second fraction, bulky household refuse, consists of worn out furniture, electrical appliances, etc. It is collected at the curbside or at fixed drop-off points such as municipal container parks. This fraction represented about $22 \%$ of all residential solid waste in 2004. Finally, municipal waste consists of solid waste collected by municipal services. Typical sources are street cleaning, garbage bins in public places, clean up of illegal waste dumps, etc. Its share amounted to only 3\% of all residential solid waste in 2004 .

When all residential solid waste objectives for a certain level are achieved, the municipalities receive a grant. Although final goals must be met in 2004, transitional achievements are evaluated by means of specific intermediate targets. In Table 1 we give a brief overview of the most important goals and grants for the residential solid waste cluster.

\section{INCLUDE TABLE 1 ABOUT HERE}

Notice that ambition level three has no precise quantitative goals. To participate at this level, municipalities must develop, among others, special projects concerning residential solid waste management in return for a grant amounting up to maximally $75 \%$ of project costs. For the residential solid waste cluster, none of the 308 Flemish municipalities participated at ambition level three and, therefore, we will not consider this ambition level in the sequel anymore.

\footnotetext{
${ }^{3}$ Solid waste generated by companies, schools, hospitals, prisons etc. is collected by private waste collection and processing firms and is not included in the definition of residential solid waste.

${ }^{4}$ In Flemish municipalities, separate collection systems exist for paper and hardboard, glass, plastic and metal packaging, vegetable, fruit and garden waste (composting waste), hazardous waste (batteries, paint residuals etc.), construction and demolition waste etc. Details are available in OVAM (2005).
} 


\subsection{First inspection of data on residential solid waste generation in Flemish municipalities}

All residential waste is automatically weighed when presented at a waste disposal facility like landfills or incineration plants. These data are reported to the Public Waste Agency of Flanders (OVAM) because they are the basis of an environmental tax on dumping and incineration of waste. Therefore, a complete dataset of residential solid waste for all 308 Flemish municipalities is available for the period 1997 - 2005 and was kindly provided to us by OVAM. The list of participating municipalities during the period (2002-2003) was given to us by Centraal Aanspreekpunt Lokale Overheden (CAPLO), the division of the Flemish regional environmental authorities responsible for coordinating the voluntary cooperation agreements. All data on socioeconomic characteristics of municipalities we collected from the Belgian federal statistical office (i.e., Statistics Belgium ${ }^{5}$ ) and the Flemish regional statistical office ${ }^{6}$.

In Table 2 we compare annual residential solid waste generation per capita along with some socio-demographic variables for different groups before and after subscribing to the voluntary cooperation agreement. The first two columns (“All municipalities") refer to the averages over all 308 Flemish municipalities. The subsequent columns report group averages for nonsubscribers and subscribers at ambition level one and two respectively. We compare residential solid waste levels between 2001 (before treatment) and 2005 (after treatment) for each group ${ }^{7}$.

\section{INCLUDE TABLE 2 ABOUT HERE}

By 2005 , about $52 \%$ of Flemish municipalities had subscribed to ambition level one but only about $25 \%$ subscribed to level two of the cluster residential solid waste of the voluntary cooperation agreement. About $22 \%$ of municipalities chose to remain outside the agreement.

\footnotetext{
${ }^{5}$ Algemene Directie Statistiek en Economische Informatie, http://statbel.fgov.be.

${ }^{6}$ Administratie Planning en Statistiek (APS), http://aps.vlaanderen.be/.

${ }^{7}$ Even though final waste targets had to be met by the end of the year 2004 already, we included one additional year to allow for a possible time lag before the program reaches its full effectiveness.
} 
Residential solid waste figures reveal considerable differences between subscribers and nonsubscribers before and after signing the voluntary agreement. Subscribers at level one have reduced their per capita residential solid waste the most: about $24 \mathrm{~kg}$ per capita or $13 \%$ between 2001 and 2005. But also in non-subscribing municipalities, solid residential waste per capita declined by more than $22 \mathrm{~kg}$ per capita or $12 \%$. Somewhat surprisingly, municipalities subscribing at the highest ambition level, managed to reduce their per capita waste levels only by about $15 \mathrm{~kg}$ or $10 \%$ between 2001 and 2005 .

Income per capita and population density appear to be higher for subscribers at level two. This seems to indicate richer and more urbanized municipalities have chosen to sign the cooperation agreement at the highest ambition level.

\subsection{Ordinary Difference-in-Difference}

The data in Table 2 can be used to compute the ordinary difference-in-differences estimator of the treatment effect of the voluntary agreement. Recalling section 3, the real treatment effect of the voluntary agreement equals progress achieved by participants minus progress by nonparticipants. Municipalities at level one reduced their residential solid waste by $13.37 \%$, whereas non-subscribing municipalities achieved $12.31 \%$ reduction during the same period. The real treatment effect for level one is, therefore, a reduction by $13.37-12.31=1.06 \%$ only $^{8}$. For the most ambitious subscription level two of the voluntary agreement, we obtain a treatment effect of $10.01-12.31=-2.30 \%$. The negative sign here means that level two municipalities produced, on average, more instead of less waste than what could be expected taking into account the progress achieved by non-subscribers.

\footnotetext{
${ }^{8}$ In order to test whether these differences are statistically significant, we regressed percentage reduction of residential waste between 2001 and 2005 on a constant and two dummy variables taking value one for subscribers at level one and two respectively and value zero for the non-subscribers. The estimated treatment effects for subscribers at level one and two proved both to be statistically insignificant, even at the $10 \%$ confidence level.
} 
Recall that this conclusion depends on the equal trend assumption behind the ordinary DiD estimator, i.e., subscribers are assumed to be able to achieve the same progress (in percentage terms) as non-subscribers without any additional effort. Of course, this assumption can be criticized. One might argue that level two municipalities were already on a lower waste level in 2001 because they had already exploited all easy and cheap waste reduction policies before. So for them, it is very costly to achieve the same relative progress as non-subscribers because they have to turn to more expensive additional waste management tools.

\subsection{Inappropriateness of the common trend assumption}

Absolute differences in residential solid waste levels

We believe the common trend identification restriction, which is necessary to justify the use of the DiD methodology, is not appropriate in our case study. Before making our argument, we first analyze in Figure 1 the evolution of average residential solid waste levels for subscribers and non-subscribers.

\section{INCLUDE FIGURE 1 ABOUT HERE}

As can be seen from Figure 1, average residential solid waste per capita decreases steadily for the groups of non-subscribing and level one municipalities between 1997 and 2003 and levels off afterwards. Throughout, there are little differences between non-subscribers and municipalities at level one. The evolution of residential solid waste levels for municipalities at ambition level two reveals a very similar pattern but these municipalities entered the voluntary policy program in 2002 at a considerably lower waste level than level one participants or nonsubscribers. Notice also that average residential solid waste for subscribers at level two was already below the final target of $150 \mathrm{~kg}$ per capita in 2001 , the year before the voluntary 
agreement started. So, on average, level two municipalities did not need additional reductions in order to qualify for the subsidies foreseen in the voluntary agreements.

Visual inspection of Figure 1 shows that municipalities at ambition level two experienced a somewhat more pronounced downward trend in residential solid waste levels (measured in $\mathrm{kg}$ per capita) before the voluntary policy program was implemented in 2002 than the other groups of municipalities. This indicates that assuming parallel trends for both non-treated and treated municipalities might be problematic, at least for level two municipalities and for the period preceding the start of the voluntary agreement in 2002 . We tested this hypothesis explicitly by means of ANOVAs on the group average absolute reductions achieved in the years prior to subscription. ${ }^{9}$ Summarizing, the ANOVA results reveal significant differences (at the $10 \%$ confidence level) between level two municipalities and other types of municipalities in several years.

Strictly speaking, this argument cannot be considered as a validity test of the parallel trend assumption underlying the DiD methodology because this assumptions cannot be tested by definition. The identification restriction refers to the counterfactual situation that treated subjects would not have taken treatment. However, since municipalities that eventually signed up at level two were already behaving differently from other municipalities before treatment started, we believe it is highly unlikely that later, once treatment has started, they would behave similarly to non-treated municipalities in the counterfactual situation that there were no treatment.

\section{Percentage differences in residential solid waste levels}

We argued before that, due to rising marginal costs of additional waste management policies, it is very demanding for subscribed municipalities to achieve the same absolute waste level

\footnotetext{
${ }^{9}$ Due to space limitations, we do not report the details of these ANOVAs. The results are available from the authors upon simple request.
} 
reductions than the control group. In order to accommodate for the differences in starting levels, we now turn to analyzing the relative waste reductions, i.e. percentage reduction rates. Figure 2 shows annual percentage changes in residential solid waste for the three groups of municipalities.

\section{INCLUDE FIGURE 2 ABOUT HERE}

The graph in Figure 2 shows that level two municipalities achieved a higher reduction percentage (i.e. deeper cuts) than the other municipalities, particularly in the period before 2002 . However, from 2002 onwards, level two municipalities do no longer systematically outperform non-subscribing and level one municipalities in terms of average percentage residential solid waste reduction. We tested also this hypothesis by means of ANOVAs, this time on the group average percentage reductions achieved in the years prior to subscription. Again, results from the ANOVAs reveal significant differences (at the $5 \%$ confidence level) between level two municipalities and other types of municipalities. Hence, also in percentage terms, there seem to be significant differences in trends between treated municipalities and the control group. We therefore conclude that, both in absolute or in percentage changes, the common trend assumption underlying the ordinary DiD technique is hard to justify in our case study.

\section{Dynamic DiD or difference-in-difference-in-differences (DiDiD) estimator}

\subsection{Intuitive description}

Therefore, we turn to a more flexible analysis that allows for more heterogeneity among the treated and non-treated subjects than in the ordinary difference-in-differences technique. We employ a similar methodology as described theoretically in Moffitt (1991) and applied in, for instance, Bratberg et al. (2005) to evaluate of the Sofia Protocol controlling transboundary emissions of nitrogen oxides. In addition to the analysis by Bratberg et al. (2005), we 
distinguish between two different subgroups of treated subjects depending on the ambition level the municipality has chosen in the voluntary agreement with the Flemish environmental administration.

The idea behind dynamic $\mathrm{DiD}$ estimators is to compare the change in progress (instead of progress as such) in periods before and periods after treatment between participants and nonparticipants. In other words the change in trend after treatment for the treated group is corrected for the simultaneous change in trend for the non-treated group. The key assumption behind this methodology is that the expected difference in the change in outcome in the absence of treatment should be the same for the treatment group (= not observed, counterfactual) as for the non-treatment group (= observed). Notice that the equal change in trend assumption replaces the parallel-trend assumption underlying the ordinary DiD methodology. Under the equal change in trends assumptions, the trends themselves are not restricted to be identical between treated and non-treated municipalities.

We tested whether second differences, i.e. changes in trend, are significantly different between the groups in the years prior to the voluntary waste management program using ANOVA. The test cannot reject the hypothesis that changes in trends are equal for any pair of groups within any year before treatment.

Finally, it should be noted that the DiDiD approach encompasses the DiD methodology. In the worst case, the more complicated DiDiD methodology does not improve over a simpler DiD analysis and the additional effect can be tested in an appropriate regression model (see section 6).

\subsection{Formal derivation}

Assume the outcome variable $y_{i, t}$, i.e., residential solid waste per capita, for municipality i in year $t$ is generated by the following stochastic process: 


$$
\begin{array}{ll}
\mathrm{y}_{\mathrm{i}, \mathrm{t}}^{0}=\alpha+\gamma \mathrm{t}+\delta^{0} \mathrm{~S}_{\mathrm{i}, \mathrm{t}}^{0}[\mathrm{t}-\mathrm{s}]+\varepsilon_{\mathrm{i}, \mathrm{t}} & \text { for non-signatories } \\
\mathrm{y}_{\mathrm{i}, \mathrm{t}}^{\mathrm{k}}=\alpha+\left[\gamma+\theta^{\mathrm{k}}\right] \mathrm{t}+\beta^{\mathrm{k}} \mathrm{L}_{\mathrm{i}}^{\mathrm{k}}+\delta^{\mathrm{k}} \mathrm{S}_{\mathrm{i}, \mathrm{t}}^{\mathrm{k}}[\mathrm{t}-\mathrm{s}]+\varepsilon_{\mathrm{i}, \mathrm{t}} & \text { for signatories at level } \mathrm{k}=1,2
\end{array}
$$

where $t$ denotes a particular time period and $\mathrm{s}$ denotes the year the voluntary program has started. $\mathrm{L}_{\mathrm{i}}^{\mathrm{k}}$ are static (i.e., time independent) dummy variables taking value 1 if the observed unit has signed the voluntary agreement at least once between 2002 and 2004, and value zero if it has never signed. The superscript $\mathrm{k}$ refers to the ambition level at which municipality $\mathrm{i}$ has signed $\operatorname{up}^{10}\left(\mathrm{k}=1\right.$ for entry level one and $\mathrm{k}=2$ for the more ambitious level two). $\mathrm{S}_{\mathrm{i}, \mathrm{t}}^{\mathrm{k}}$ are dynamic (i.e., time dependent) dummy variables for signatories at level one and two taking value zero for all periods before actual subscription and value 1 afterwards ${ }^{11} . S_{i, t}^{0}$ is the counterpart for the non-signatories taking value zero before the start of the voluntary program and value 1 afterwards. Finally, the $\varepsilon_{i, t}$ are stochastic error terms which are assumed to be normally and independently distributed with zero mean and constant variance: $\varepsilon_{\mathrm{i}, \mathrm{t}} \square \mathrm{NID}\left(0, \sigma^{2}\right)$.

As for the parameters of this stochastic model, $\alpha$ denotes a common constant absolute waste level for both subscribers and non-subscribers over the entire time horizon of the analysis. $\gamma$ is the time trend experienced by non-subscribers over the entire time horizon. Subscribers on the other hand, experience a specific time trend $\gamma+\theta^{k}$ in the pre-treatment period. Hence, the $\theta^{k}$ coefficients measure the additional time trend characterizing subscribers at level k compared to the common time trend $\gamma$ experienced by non-subscribing municipalities. The $\beta^{\mathrm{k}}$ coefficients measure the signatories' group specific effects to account for permanent differences between

\footnotetext{
${ }^{10}$ For municipalities that started at level one and moved on to level two some years later, we only take into account the highest ambition level. Hence, $\mathrm{L}_{\mathrm{i}}^{1}=0$ and $\mathrm{L}_{\mathrm{i}}^{2}=1$ for such municipalities.

${ }^{11}$ These variables indicate the real subscription status of individual municipalities. If a municipality subscribed at level one for the first two years and moved on to level two during the third year, this will be coded as $\mathrm{S}_{\mathrm{i}, \mathrm{t}}^{1}=(0,0,1,1,0)$ and $\mathrm{S}_{\mathrm{i}, \mathrm{t}}^{2}=(0,0,0,0,1)$ respectively.
} 
subscribers and non-subscribers (for instance differences in starting positions). The additional change in trend that participating subjects are undergoing after signing up to the voluntary agreement is measured by $\delta^{\mathrm{k}}$. The model also allows for the possibility that municipalities in the control group would experience an additional change in trend (measured by $\delta^{0}$ ) after the starting date of the voluntary agreement, even though they do not participate in the agreement ${ }^{12}$. It is important to note is that the model is sufficiently flexible to allow for differences in time trends between the three groups, both before and after participating in the voluntary agreement. By calculating the difference (using expression (1)) between the change in average outcome for the treated at level $\mathrm{k}(\mathrm{k}=1,2)$ in two subsequent pre-treatment periods $\mathrm{b}$ and $\mathrm{b}-1$ and their change in average outcome in two subsequent post-treatment periods a and a-1, it can be shown that $\delta^{\mathrm{k}}$ measures the change in trend for the subscribers at level $\mathrm{k}$ before and after subscription:

$$
\mathrm{E}\left[\Delta \Delta \overline{\mathrm{y}}^{\mathrm{k}}\right]=\left\{\mathrm{E}\left[\overline{\mathrm{y}}_{\mathrm{a}}^{\mathrm{k}}\right]-\mathrm{E}\left[\overline{\mathrm{y}}_{\mathrm{a}-1}^{\mathrm{k}}\right]\right\}-\left\{\mathrm{E}\left[\overline{\mathrm{y}}_{\mathrm{b}}^{\mathrm{k}}\right]-\mathrm{E}\left[\overline{\mathrm{y}}_{\mathrm{b}-1}^{\mathrm{k}}\right]\right\}=\left\{\gamma+\theta^{\mathrm{k}}+\delta^{\mathrm{k}}\right\}-\left\{\gamma+\theta^{\mathrm{k}}\right\}=\delta^{\mathrm{k}}
$$

Similarly, $\delta^{0}$ measures the possible change in trend for the non-subscribers before and after the voluntary agreements came into effect:

$$
\mathrm{E}\left[\Delta \Delta \overline{\mathrm{y}}^{0}\right]=\left\{\mathrm{E}\left[\overline{\mathrm{y}}_{\mathrm{a}}^{0}\right]-\mathrm{E}\left[\overline{\mathrm{y}}_{\mathrm{a}-1}^{0}\right]\right\}-\left\{\mathrm{E}\left[\overline{\mathrm{y}}_{\mathrm{b}}^{0}\right]-\mathrm{E}\left[\overline{\mathrm{y}}_{\mathrm{b}-1}^{0}\right]\right\}=\left\{\gamma+\delta^{0}\right\}-\{\gamma\}=\delta^{0}
$$

Using (2) and (3), we can now define the DiDiD estimator of the pure treatment effect at ambition level $\mathrm{k}(\mathrm{k}=1,2)$ as follows:

$$
\mathrm{E}\left[\hat{\delta}_{\mathrm{DDD}}^{\mathrm{k} 0}\right]=\mathrm{E}\left[\Delta \Delta \overline{\mathrm{y}}^{\mathrm{k}}\right]-\mathrm{E}\left[\Delta \Delta \overline{\mathrm{y}}^{0}\right]=\delta^{\mathrm{k}}-\delta^{0}
$$

This estimator measures the effect of the voluntary agreement on the change in performance of the subscribers after correcting for the change in performance by the non-subscribers.

Note that we can measure the incremental effect of the different ambition levels in the voluntary agreements by calculating:

\footnotetext{
${ }^{12}$ For instance, this could be due to a general economic depression starting at the same moment as the start of the voluntary agreements, or to spill-over effects from treated municipalities.
} 


$$
\mathrm{E}\left[\hat{\delta}_{\mathrm{DDD}}^{21}\right]=\mathrm{E}\left[\Delta \Delta \overline{\mathrm{y}}^{2}\right]-\mathrm{E}\left[\Delta \Delta \overline{\mathrm{y}}^{1}\right]=\delta^{2}-\delta^{1}
$$

This estimator measures the additional trend change that can be attributed to switch from ambition level one to level two in the voluntary agreement.

In order to test for the robustness of treatment effects, it is convenient to implement the DiDiD estimator in a statistical regression framework. Taking differences for both equations in (1), we obtain:

$$
\begin{aligned}
\mathrm{y}_{\mathrm{i}, \mathrm{t}}^{\mathrm{k}}-\mathrm{y}_{\mathrm{i}, \mathrm{t}-1}^{\mathrm{k}}= & \left\{\alpha+\left[\gamma+\theta^{\mathrm{k}}\right] \mathrm{t}+\beta^{\mathrm{k}} \mathrm{L}_{\mathrm{i}}^{\mathrm{k}}+\delta^{\mathrm{k}} \mathrm{S}_{\mathrm{i}, \mathrm{t}}^{\mathrm{k}}[\mathrm{t}-\mathrm{s}]+\varepsilon_{\mathrm{i}, \mathrm{t}}\right\} \\
& -\left\{\alpha+\left[\gamma+\theta^{\mathrm{k}}\right][\mathrm{t}-1]+\beta^{\mathrm{k}} \mathrm{L}_{\mathrm{i}}^{\mathrm{k}}+\delta^{\mathrm{k}} \mathrm{S}_{\mathrm{i}, \mathrm{t}-1}^{\mathrm{k}}[\mathrm{t}-1-\mathrm{s}]+\varepsilon_{\mathrm{i}, \mathrm{t}-1}\right\} \\
= & \gamma+\theta^{\mathrm{k}}+\delta^{\mathrm{k}} \mathrm{S}_{\mathrm{i}, \mathrm{t}-1}^{\mathrm{k}}+\varepsilon_{\mathrm{i}, \mathrm{t}}-\varepsilon_{\mathrm{i}, \mathrm{t}-1} \quad \text { for signatories at level } \mathrm{k}=1,2
\end{aligned}
$$

and $^{13}$ :

$$
\begin{aligned}
\mathrm{y}_{\mathrm{i}, \mathrm{t}}^{0}-\mathrm{y}_{\mathrm{i}, \mathrm{t}-1}^{0} & =\left\{\alpha+\gamma \mathrm{t}+\delta^{0} \mathrm{~S}_{\mathrm{i}, \mathrm{t}}^{0}[\mathrm{t}-\mathrm{s}]+\varepsilon_{\mathrm{i}, \mathrm{t}}\right\}-\left\{\alpha+\gamma[\mathrm{t}-1]+\delta^{0} \mathrm{~S}_{\mathrm{i}, \mathrm{t}-1}^{0}[\mathrm{t}-1-\mathrm{s}]+\varepsilon_{\mathrm{i}, \mathrm{t}-1}\right\} \\
& =\gamma+\delta^{0} \mathrm{~S}_{\mathrm{i}, \mathrm{t}-1}^{0}+\varepsilon_{\mathrm{i}, \mathrm{t}}-\varepsilon_{\mathrm{i}, \mathrm{t}-1} \quad \text { for nonsignatories }
\end{aligned}
$$

Grouping both equations (6) and (7) and defining a new error term $v_{i, t}=\varepsilon_{i, t}-\varepsilon_{i, t-1}$ we can write:

$$
\mathrm{y}_{\mathrm{i}, \mathrm{t}}-\mathrm{y}_{\mathrm{i}, \mathrm{t}-1}=\gamma+\theta^{1} \mathrm{~L}_{\mathrm{i}}^{1}+\theta^{2} \mathrm{~L}_{\mathrm{i}}^{2}+\delta^{0} \mathrm{~S}_{\mathrm{i}, \mathrm{t}-1}^{0}+\delta^{1} \mathrm{~S}_{\mathrm{i}, \mathrm{t}-1}^{1}+\delta^{2} \mathrm{~S}_{\mathrm{i}, \mathrm{t}-1}^{2}+\mathrm{v}_{\mathrm{i}, \mathrm{t}} \quad \forall \mathrm{i}
$$

Estimates of the coefficients in this equation can be used to test the statistical significance of the treatment effects.

\subsection{Graphical interpretation}

Graphically (see Figure 3) the DiDiD treatment effect can be derived by extrapolating the pretreatment trend (dotted lines in Figure 3) to the after treatment period. The differences between the extrapolated and the real value for both groups are the corresponding changes in trend (here denoted by $\Delta \Delta \bar{y}^{\mathrm{k}}$ for the participating group and $\Delta \Delta \overline{\mathrm{y}}^{0}$ for the non-participating group). The treatment effect can be seen as $\Delta \Delta \overline{\mathrm{y}}^{\mathrm{k}}-\Delta \Delta \overline{\mathrm{y}}^{0}$.

\footnotetext{
${ }^{13}$ Note that $\mathrm{S}_{\mathrm{i}, \mathrm{t}}^{\mathrm{k}}-\mathrm{S}_{\mathrm{i}, \mathrm{t}-1}^{\mathrm{k}}$ equals zero if $\mathrm{t} \neq \mathrm{S}$ and equals one otherwise.
} 


\section{INCLUDE FIGURE 3 ABOUT HERE}

\subsection{Additional explanatory variables}

In addition to the formulation in equation (8) we have augmented the model with two more explanatory variables in order to be able to test two important hypotheses. Inspection of Figure 1 revealed a gradual decline over time of residential solid waste reduction effort by signatories of the voluntary agreement at level two, but the rate of decline diminishes (and even becomes an increase in the very last year of observation). In our opinion, there are two possible hypotheses for explaining the leveling off of waste reduction effort by the subscribers.

First, one might argue that due to increasing marginal costs of reduction efforts, it becomes harder to reduce residential waste further. The leveling off is then just a reflection of the rising incremental costs to achieve further progress. More intuitively, once the low hanging fruits have been picked, municipalities have to revert to more expensive policies to reduce residential waste further. Unfortunately we have no data on the expenditures of municipalities on specific actions to reduce their residential waste level by means of information campaigns, etc. Hence we cannot test this hypothesis directly, but we tried instead to find a proxy variable for the increasing reduction effort over time. In particular, we used cumulative reduction with respect to 1997 $\left(\mathrm{CR}_{\mathrm{i}, \mathrm{t}}=\mathrm{y}_{\mathrm{i}, 1997} / \mathrm{y}_{\mathrm{i}, \mathrm{t}-1}\right)$ as a proxy variable for testing our rising marginal abatement costs hypothesis. If this hypothesis were true, we expect that a municipality that has cumulatively reduced its waste level strongly by a given year t compared to 1997, will achieve less progress in curbing its garbage production further. So we expect a positive $\operatorname{sign}^{14}$ for the estimated coefficient for the cumulative reduction variable if the rising marginal reduction cost hypothesis holds.

\footnotetext{
${ }^{14}$ Positive because $y_{i, t}-y_{i, t-1}$, i.e. change of $y$, is on average negative for all municipalities. Hence, leveling off of reduction effort means that $y_{i, t}-y_{i, t-1}$ becomes "less negative", i.e. greater as cumulative reduction w.r.t. 1997 increases.
} 
Secondly, one might argue that subscribing municipalities feel little incentive to reduce their garbage production below $200 \mathrm{~kg}$ (level one) or $150 \mathrm{~kg}$ (level two) per capita because this is the level for being eligible for receiving the subsidy under the voluntary cooperation agreement. We will call this the incentive hypothesis. To test for this incentive effect, we constructed dynamic dummy variables $G_{i, t}^{k}$ defined as $G_{i, t}^{1}=0$ as long as $y_{i, t-1}>200$ and $G_{i, t}^{1}=1$ otherwise for level one. Similarly, $\mathrm{G}_{\mathrm{i}, \mathrm{t}}^{2}=0$ as long as $\mathrm{y}_{\mathrm{i}, \mathrm{t}-1}>150$ and $\mathrm{G}_{\mathrm{i}, \mathrm{t}}^{2}=1$ otherwise for level two. We expect that if the gap to the norm becomes smaller, and surely after reaching the norm of 200 and $150 \mathrm{~kg}$, the municipality might do less effort to achieve further reduction. Hence, high values of $\mathrm{G}_{\mathrm{i}, \mathrm{t}}^{\mathrm{k}}$ should correspond to lower rates of reduction in residential solid waste in order to be consistent with the incentive hypothesis. In other words, we expect a positive ${ }^{15}$ sign for the estimated coefficients for these variables in the regression.

To summarize, the final model estimated can be expressed as follows:

$$
\Delta \% \mathrm{y}_{\mathrm{i}, \mathrm{t}}=\gamma+\theta^{1} \mathrm{~L}_{\mathrm{i}}^{1}+\theta^{2} \mathrm{~L}_{\mathrm{i}}^{2}+\delta^{0} \mathrm{~S}_{\mathrm{i}, \mathrm{t}-1}^{0}+\delta^{1} \mathrm{~S}_{\mathrm{i}, \mathrm{t}-1}^{1}+\delta^{2} \mathrm{~S}_{\mathrm{i}, \mathrm{t}-1}^{2}++\mu \mathrm{CR}_{\mathrm{i}, \mathrm{t}}+\lambda^{1} \mathrm{G}_{\mathrm{i}, \mathrm{t}}^{1}+\lambda^{2} \mathrm{G}_{\mathrm{i}, \mathrm{t}}^{2}+\mathrm{v}_{\mathrm{i}, \mathrm{t}}
$$

with $\Delta \% \mathrm{y}_{\mathrm{i}, \mathrm{t}}$ measuring the year-to-year percentage change in residential solid waste levels ${ }^{16}$. We expect $\delta^{1}-\delta^{0}<0$ and $\delta^{2}-\delta^{0}<0$ if the voluntary agreements are really effective at ambition level one and two, respectively. In addition, we expect $\delta^{2}-\delta^{1}<0$ if level two is leading to more reduction efforts than level one. If the rising marginal cost hypothesis and the incentive hypothesis hold, we expect to find $\mu>0, \lambda^{1}>0$ and $\lambda^{2}>0$, respectively.

\footnotetext{
${ }^{15}$ See previous footnote

${ }^{16}$ Note that in the final estimation equation (9) the dependent variable is written in terms of percentage changes instead of absolute changes as in expression (8). However, both formulations can be shown to be equivalent by taking a logarithmic transformation of the $y_{i, t}$ variables in the stochastic process (1).
} 


\section{Regression results}

\subsection{Reference estimation}

Results of the DiDiD regression analysis are presented in Table 3. The estimated coefficients were obtained using the full time horizon of the dataset, i.e. 2000-2005.

\section{INCLUDE TABLE 3 ABOUT HERE}

The annual percentage change in residential solid waste by non-subscribing municipalities is negative $(\gamma=-0.029)$ and is statistically different from zero at the $10 \%$ confidence interval. In comparison to non-subscribers, subscribers at level one experience an additional decrease of $\theta^{1}=-0.035$ of their residual waste levels, and subscribers at level two of $\theta^{2}=-0.043$. Both of these trend changes are significantly different from zero at the $5 \%$ confidence level. We can therefore conclude that subscribers are on a significantly steeper reduction trajectory than nonsubscribers when we consider the full time horizon of 2000-2005. However, there is no significant difference between both levels of subscription, i.e., the hypothesis $\mathrm{H}_{0}: \theta^{1}=\theta^{2}$ is not rejected by the data ${ }^{17}$.

After subscription, municipalities at level one experience a significant additional downward trend change $\delta^{1}=-0.024$ per annum. At first sight, level two municipalities are confronted with a trend reversal because $\delta^{2}=+0.005$ but this coefficient is not statistically significant. These observations lead us to conclude that the voluntary agreements induce level one municipalities to reduce their residential solid waste stronger than their business-as-usual time

\footnotetext{
${ }^{17}$ The F-test for this joint parameter hypothesis is computed using the heteroscedasticity consistent covariance matrix. Value of $\chi^{2}=0.33$ and $\mathrm{p}=0.567$.
} 
trend. However, at the more ambitious level two, we do not observe an additional reduction in annual waste levels; on the contrary, we observe a trend reversal. ${ }^{18}$

In order to assess the effectiveness of the voluntary agreements, we argued before that we should compare the progress of the treated to the progress of the non-treated. Note that the nonsubscribed municipalities achieved an additional statistically significant reduction of $\delta^{0}=-0.030$ per annum from 2002 onwards. Hence, although they did not join the voluntary agreement (and therefore did not qualify for subsidies), non-subscribing municipalities achieved strong reductions of their residential solid waste in the same period of time.

Using the minus $3.0 \%$ trend change from the non-subscribers as reference point, we find that the treatment effect at ambition level one is slightly positive $\left(\delta^{1}-\delta^{0}=+0.006\right)$, but it is not significantly different from zero. So progress by subscribers at level one and non-subscribers are statistically undistinguishable. However, for municipalities participating at ambition level two, we find evidence for a positive treatment effect $\delta^{2}-\delta^{0}=+0.035$ which is statistically significant at the $10 \%$ level (and almost at the 5\% level). This sign is different than expected and implies that, on average, municipalities at level two achieved 3.5\% lower change in trend of their residential solid waste levels compared to what could be expected on the basis of the performance of non-subscribers. We also tested the difference between $\delta^{2}$ and $\delta^{1}$ which measures the difference in evolution of the trends of subscribers at level one and two. The positive coefficient suggests that municipalities participating at level two achieved less reduction of their residential solid waste levels compared to what could be expected based on the performance of subscribers at level one. We conclude that neither of the two ambition levels of the voluntary agreements achieved more reduction effort than the one achieved by non-

\footnotetext{
${ }^{18}$ This type of argument refers to what is called "difference" estimators, see Moffit (1991). It compares progress before and after treatment of participants without reference to non-participants.
} 
subscribers. Level one municipalities achieved approximately the same progress as nonsubscribers. However, level two municipalities experienced a trend reversal.

Note that the DiDiD estimator is a generalization of the ordinary DiD estimator we discussed before. In particular, if $\theta^{\mathrm{k}}=\delta^{0}=0$ in equation (8), we recover the simple DiD estimator for $\mathrm{t}=\mathrm{s}$. Clearly, looking at the regression results in table 3 , both $\theta^{\mathrm{k}}$ and $\delta^{0}$ differ significantly from zero, meaning the more complicated DiDiD methodology generates additional insight over the ordinary DiD analysis.

The estimated coefficient of variable $\mathrm{CR}_{\mathrm{i}, \mathrm{t}}$ is positive and statistically significant at the $1 \%$ confidence level. Hence, the hypothesis that rising marginal reduction costs negatively effects residential solid waste reduction is supported (or at least not refuted) by the data.

The estimated coefficients relating to the incentive hypothesis, i.e., variables $G_{i, t}^{k}$, are also significantly different from zero at the $1 \%$ level with the expected positive sign. The data do not reject the hypothesis that municipalities refrained from additional effort once they have reached the final waste objective of the ambition level they have subscribed to.

\subsection{Sensitivity analysis}

In order to assess the robustness of our estimates, we performed a number of additional regressions. In a first series of regressions, only municipalities with an annual amount of residential solid waste equal or greater than a certain limit - (1) $150 \mathrm{~kg} / \mathrm{cap}$, (2) $155 \mathrm{~kg} / \mathrm{cap}$, (3) $160 \mathrm{~kg} / \mathrm{cap}$, and (4) $165 \mathrm{~kg} / \mathrm{cap}$ - were included in the analysis. In this way, we try to test whether municipalities who were in 2001 still far from achieving the required waste levels by 2004, are perhaps more sensitive to treatment than other municipalities that were already closer to the limit. However, results in Table 4 indicate that the estimated values of the treatment effects hardly change and they all remain statistically insignificant. 


\section{INCLUDE TABLE 4 ABOUT HERE}

A second sensitivity analysis refers to the year treatment might become visible in the observed waste data. Although intermediate waste targets had to be met from the first year of the agreement onwards in order to qualify for subsidies, we tested whether our estimates would change if we allow for one additional year before the agreement attaining its full effectiveness. In other words, we re-estimated the model under the alternative assumption that the presumed treatment effect would become visible only from the second year after the start of treatment instead of immediately. This is done by shifting the date $s$ in expression (1) forward by one year and by rearranging all participation dummy variables correspondingly. Again, we find little change in the results. The treatment effects for both ambition levels are still positive but insignificant. Since the coefficients and their corresponding p-values hardly differ from the reference estimation results, we do not report the output of this additional regression. Detailed results are available from the authors upon simple request.

\section{Conclusions}

Our main objective with this paper is to give a brief introduction to quantitative evaluation techniques that can be used to evaluate the effectiveness of voluntary policy programs with nonexperimental data and to argue that these are relevant tools for assessing the effectiveness of voluntary waste management programs. We focused in particular on an extension of the DiD estimator - the dynamic difference-in-differences (DiDiD) technique that compares progress of participants to that of non-participants.

To illustrate this technique, we have studied a scheme of voluntary environmental agreements between the Flemish regional authorities and local municipalities. We focused on a specific program aimed at reducing residential solid waste in the period 2002-2004. Considering the 
whole time horizon of the program, our results indicate that municipalities subscribing at the lowest ambition level of the agreement accelerated the reduction of their residential solid waste level after entering the voluntary agreement. However, municipalities subscribing at the highest ambition level of the agreement experienced a trend reversal meaning that their residential solid waste reduction slowed down after signing the agreement.

Remarkably, also the non-subscribing municipalities have achieved strong reductions in residential solid waste levels, especially after 2002, the year the voluntary agreements started. The reason for that is that the Flemish environmental authorities use also other waste management policy instruments to influence household behavior and municipal decision making. To account for these other influences that are common to both subscribers and nonsubscribers, we subtracted progress (measured as the change in time trend observed after the start of the voluntary agreement) of non-subscribers from the progress achieved by subscribers. This procedure revealed that progress of non-subscribers and subscribers on the lowest ambition level are approximately the same. However, subscribers on the highest ambition level achieved significantly lower progress than subscribers at level one and non-subscribers.

We should stress that these results are to be interpreted with care. They only indicate that the current program is not generating additional progress compared to non-participants. The more interesting question is how to explain this result. We therefore tried to test two hypotheses to shed more light on this unexpected evaluation result. First, the data are consistent with a rising incremental cost hypothesis that subscribers have to turn to more expensive waste management policies because they have already exploited the cheaper policies prior to the subscription date. This might be interpreted as saying that subscribers are not to be blamed for lower performance, but current subsidy rates are too low and do not give sufficient incentive to undertake additional reduction effort. Secondly, the results may also be partially explained by the fact that 
subscribing municipalities refrained from additional reduction efforts once the target of the program was achieved. In the regression analysis, a gap-to-target proxy variable explained a significant part of the variability in outcomes. This latter result might indicate that current target levels, especially at level two, are not ambitious enough.

For further research, we believe other quantitative policy evaluation techniques like matching and instrumental variables type of estimators could be applied to the Flemish case study. Given the significant results obtained by our dynamic DiD analysis, we think that these alternative techniques will not yield different evaluation results in general. However, some techniques like instrumental variables techniques applied to panel data - would give additional detailed insights into the reasons why particular types of subscribers perform less than what could be expected. However, applications of such techniques require more detailed data, for instance on municipal waste pricing policies, some of which are currently not available in Flanders. 


\section{Acknowledgements}

This paper benefited strongly from the constructive suggestions by Sandra Rousseau. All remaining errors are, of course, ours. The authors gratefully acknowledge financial support by the Flemish environmental authorities AMINAL in the framework of the TWOL 2003-00164 study "Ontwikkeling coherent beleidskader voor de evaluatie van aan leefmilieu gerelateerde financiële tegemoetkomingen (vooral subsidies) en toepassing van dit evaluatiekader op een aantal cases". Data on the voluntary agreements between AMINAL and the Flemish municipalities were provided by Mrs. K. Paepen (AMINAL-CAPLO), Mr. Wille (OVAM) and Mrs. Putseys (OVAM). The authors also thank T. Van Puyenbroeck (EHSAL) for proofreading and useful suggestions on the content of the manuscript. Comments by participants of seminars at the Center for Advanced Study in Oslo, Katholieke Universiteit Leuven and the 3th International Conference on Waste Management and the Environment in Malta are gratefully acknowledged. For the econometric part of the work, we benefited from discussions with E. Omey (EHSAL) and J. Hendrickx (EHSAL). Part of this work was written during a research stay of Johan Eyckmans at the Center for Advanced Studies in Oslo, Norway. Financial and practical support by the CAS staff is gratefully acknowledged. 


\section{References}

[1] Bjørner, T.B. and Jensen H.H., 2002. Energy taxes, voluntary agreements and investment subsidies - a micro-panel analysis of the effect on Danish industrial companies' energy demand. Resource and Energy Economics 24, 229-249

[2] Blundell, R. and M. Costa Dias, 2000. Evaluation methods for non-experimental data. Fiscal Studies 21, 427-468.

[3] Bratberg, E., Tjøtta, S. and Øines, T., 2005. Do voluntary international environmental agreements work?. Journal of Environmental Economics and Management 50, 583-597.

[4] De Jaeger, S., Eyckmans, J., Van Biervliet, K. and Van Puyenbroeck, T., 2005. Eindrapport “Ontwikkeling coherent beleidskader voor de evaluatie van aan leefmilieu gerelateerde financiële tegemoetkomingen (vooral subsidies) en toepassing van dit evaluatiekader op een aantal cases". EHSAL, Brussel, Belgium (In Dutch).

[5] Heckman J. J. (1979), Sample Selection Bias as a Specification Error. Econometrica 47, $153-161$.

[6] Heckman, J., Ichimura, H., and Todd, P. (1998a). Matching as an econometric evaluation estimator. Review of Economic Studies 65, 261-294.

[7] Heckman, J., Ichimura, H., Smith, J. and Todd, P. (1998b). Characterizing selection bias using experimental data. Econometrica 66, 1017-1098.

[8] Khanna, M. and Damon, L.A., 1999. EPA's voluntary 33/50 program: impact on toxic releases and economic performance of firms. Journal of Environmental Economics and Management 37, 1-25.

[9] Kinnaman, T.C. and Fullerton, D., 2000. Garbage and recycling with endogenous local policy, Journal of Urban Economics 48, 419-442. 
[10] Meyer, B.D., 1995. Natural and quasi-experiments in economics, Journal of Business \& Economic Statistics 13, 151-161.

[11] Mickwitz, P., 2003. A framework for evaluating environmental policy instruments context and key concepts. Evaluation 9, 415-436.

[12] Millock, K. and Nauges, C., 2006. Ex Post Evaluation of an Earmarked Tax on Air Pollution. Land Economics 82, 68-84.

[13] Ministerie van de Vlaamse Gemeenschap, 2001. Samenwerkingsovereenkomst Vlaams Gewest - gemeenten, milieu als opstap naar duurzame ontwikkeling, contracttekst 20022004. Ministerie van de Vlaamse Gemeenschap, Brussel, Belgium (in Dutch).

[14] Moffitt, R., 1991. Program evaluation with nonexperimental data. Evaluation Review $15,291-314$.

[15] OECD, 2003. Voluntary approaches for environmental policies, effectiveness, efficiency and usage in policy mixes, OECD Publications Service, Paris.

[16] OVAM, 2005. Inventarisatie huishoudelijke afvalstoffen 2004. OVAM, Mechelen, Belgium (in Dutch).

[17] Shadish, W. R., Cook, T.D. and Campbell, D.T., 2002. Experimental and Quasiexperimental Designs for Generalized Causal Inference, Houghton Mifflin Company, Boston and New York, USA

[18] Segerson, K. and Miceli T.J., 1998. Voluntary environmental agreements: good or bad news for environmental protection? Journal of Environmental Economics and Management $36,109-130$.

[19] Verbeek, M., 2000. A Guide to Modern Econometrics, John Wiley \& Sons, Chichester, UK and New York, USA. 
Table 1: Quantitative waste objectives and subsidies

\begin{tabular}{|c|c|c|c|c|}
\hline & 2002 & 2003 & 2004 & Annual grant \\
\hline Ambition level 1 & $220 \mathrm{~kg} / \mathrm{cap}$ & $220 \mathrm{~kg} / \mathrm{cap}$ & $200 \mathrm{~kg} / \mathrm{cap}$ & $€ 0.9$ /citizen \\
\hline Ambition level 2 & $200 \mathrm{~kg} / \mathrm{cap}$ & $175 \mathrm{~kg} / \mathrm{cap}$ & $150 \mathrm{~kg} / \mathrm{cap}$ & $€ 1.6$ / citizen \\
\hline Ambition level 3 & & $<150 \mathrm{~kg} / \mathrm{cap}$ & & Max. $75 \%$ on project basis \\
\hline
\end{tabular}


Table 2: Descriptive statistics municipal data

\begin{tabular}{|c|c|c|c|c|}
\hline & All municipalities & Non-subscribers & Subscribers level 1 & Subscribers level 2 \\
\hline & before after & before & before & before \\
\hline $\begin{array}{c}\text { residential solid waste } \\
\text { [kg / capita / year }]\end{array}$ & $\begin{array}{cc}\mathbf{1 7 2 . 1 8} & \mathbf{1 5 0 . 8 6} \\
(61.60) & (48.70)\end{array}$ & $\begin{array}{ll}\mathbf{1 7 9 . 9 0} & \mathbf{1 5 7 . 7 5} \\
(51.42) & (45.68)\end{array}$ & $\begin{array}{cc}\mathbf{1 7 9 . 9 0} & \mathbf{1 5 5 . 8 5} \\
(66.49) & (52.11)\end{array}$ & $\begin{array}{cc}\mathbf{1 4 9 . 4 3} & \mathbf{1 3 4 . 4 8} \\
(53.87) & (40.06\end{array}$ \\
\hline \multicolumn{5}{|l|}{ absolute change } \\
\hline$[\mathrm{kg} /$ captita $]$ & -21.32 & -22.15 & -24.05 & -14.95 \\
\hline \multicolumn{5}{|l|}{ relative change } \\
\hline [\% change w.r.t. 2001$]$ & $-12.38 \%$ & $-12.31 \%$ & $-13.37 \%$ & $-10.01 \%$ \\
\hline family size & 2.58 & 2.58 & 2.58 & 2.57 \\
\hline [people] & $(-0.15)$ & $(-0.15)$ & $(-0.14)$ & $(-0.17)$ \\
\hline population & 19326 & 14670 & 16391 & 29504 \\
\hline [people] & $(-30476)$ & $(-14253)$ & $(-12245)$ & $(-55405)$ \\
\hline population density & 5.15 & \multirow{2}{*}{$\begin{array}{c}5.49 \\
(-5.37)\end{array}$} & \multirow{2}{*}{$\begin{array}{c}4.59 \\
(-3.41)\end{array}$} & \multirow{2}{*}{$\begin{array}{c}5.95 \\
(-5.24)\end{array}$} \\
\hline [people / ha] & $(-4.48)$ & & & \\
\hline income per capita & 12738 & 12332 & 12781 & 13010 \\
\hline$\left[\epsilon_{2001}\right.$ per capita $]$ & $(-4573)$ & $(-2279)$ & $(-5824)$ & $(-2839)$ \\
\hline observations & 308 & 69 & 161 & 78 \\
\hline fraction & $100 \%$ & $22.40 \%$ & $52.30 \%$ & $25.30 \%$ \\
\hline
\end{tabular}


Table 3: Dynamic DiD estimates

\begin{tabular}{|c|c|c|c|c|c|}
\hline & Symbol & $\begin{array}{c}\text { Parameter } \\
\text { Estimate } \\
\end{array}$ & $\begin{array}{c}\text { Standard } \\
\text { Error } \\
\end{array}$ & $\mathrm{t}$-Statistic & $\mathrm{p}$ Value \\
\hline Constant & $\gamma$ & -0.029 & 0.016 & -1.856 & 0.064 \\
\hline $\mathrm{L}_{\mathrm{i}}^{1}$ & $\theta^{1}$ & -0.035 & 0.016 & -2.254 & 0.024 \\
\hline $\mathrm{L}_{\mathrm{i}}^{2}$ & $\theta^{2}$ & -0.043 & 0.017 & -2.575 & 0.010 \\
\hline $\mathrm{S}_{\mathrm{i}, \mathrm{t}-1}^{0}$ & $\delta^{0}$ & -0.030 & 0.014 & -2.082 & 0.038 \\
\hline $\mathrm{S}_{\mathrm{i}, \mathrm{t}-1}^{1}$ & $\delta^{1}$ & -0.024 & 0.011 & -2.243 & 0.025 \\
\hline $\mathrm{S}_{\mathrm{i}, \mathrm{t}-1}^{2}$ & $\delta^{2}$ & 0.005 & 0.012 & 0.434 & 0.665 \\
\hline $\mathrm{CR}_{\mathrm{i}, \mathrm{t}}$ & $\mu$ & 0.031 & 0.008 & 3.723 & 0.000 \\
\hline $\mathrm{G}_{\mathrm{i}, \mathrm{t}}^{1}$ & $\lambda^{1}$ & 0.032 & 0.009 & 3.490 & 0.001 \\
\hline $\mathrm{G}_{\mathrm{i}, \mathrm{t}}^{2}$ & $\lambda^{2}$ & 0.039 & 0.006 & 6.283 & 0.000 \\
\hline Treatment effect 1 & $\delta^{1}-\delta^{0}$ & 0.006 & 0.018 & 0.358 & 0.720 \\
\hline Treatment effect 2 & $\delta^{2}-\delta^{0}$ & 0.035 & 0.026 & 1.951 & 0.051 \\
\hline Effect level 2 - level 1 & $\delta^{2}-\delta^{1}$ & 0.029 & 0.016 & 1.816 & 0.070 \\
\hline F Value & $\mathrm{F}$ & \multicolumn{4}{|c|}{$15.562(\mathrm{p}$ Value $=0.000)$} \\
\hline R-squared & $\mathrm{R}^{2}$ & \multicolumn{4}{|c|}{0.075} \\
\hline Adjusted R-squared & $\overline{\mathrm{R}}^{2}$ & \multicolumn{4}{|c|}{0.070} \\
\hline Observations & $\mathrm{n}$ & \multicolumn{4}{|c|}{1540} \\
\hline
\end{tabular}

Legend: all variables are explained in the text. Standard errors are heteroscedasticity robust 
Table 4: Results from sensitivity analysis

\begin{tabular}{|c|c|c|c|c|c|}
\hline \multirow[b]{2}{*}{$\begin{array}{l}\text { Criterion to include } \\
\text { municipality }\end{array}$} & \multirow[b]{2}{*}{ \# observations } & \multicolumn{4}{|c|}{ Treatment effect } \\
\hline & & Level & Value & $\begin{array}{l}\text { Standard } \\
\text { Error } \\
\end{array}$ & Probability \\
\hline \multirow{2}{*}{$\begin{array}{l}\text { residential solid waste in } \\
2001>150\end{array}$} & \multirow{2}{*}{$985(63.96 \%)$} & level 1 & 0.0060 & 0.0186 & 0.7494 \\
\hline & & level 2 & 0.0471 & 0.0269 & 0.0809 \\
\hline \multirow{2}{*}{$\begin{array}{l}\text { residential solid waste in } \\
\qquad 2001>155\end{array}$} & \multirow{2}{*}{$915(59.42 \%)$} & level 1 & 0.0118 & 0.0188 & 0.5294 \\
\hline & & level 2 & 0.0431 & 0.0284 & 0.1294 \\
\hline \multirow{2}{*}{$\begin{array}{l}\text { residential solid waste in } \\
\qquad 2001>160\end{array}$} & \multirow{2}{*}{$860(55.84 \%)$} & level 1 & 0.0139 & 0.0193 & 0.4705 \\
\hline & & level 2 & 0.0481 & 0.0295 & 0.1034 \\
\hline \multirow{2}{*}{$\begin{array}{l}\text { residential solid waste in } \\
\qquad 2001>165\end{array}$} & \multirow{2}{*}{$800(51.95 \%)$} & level 1 & 0.0145 & 0.0188 & 0.4407 \\
\hline & & level 2 & 0.0403 & 0.0302 & 0.1829 \\
\hline
\end{tabular}


Figure 1: Evolution of residential solid waste

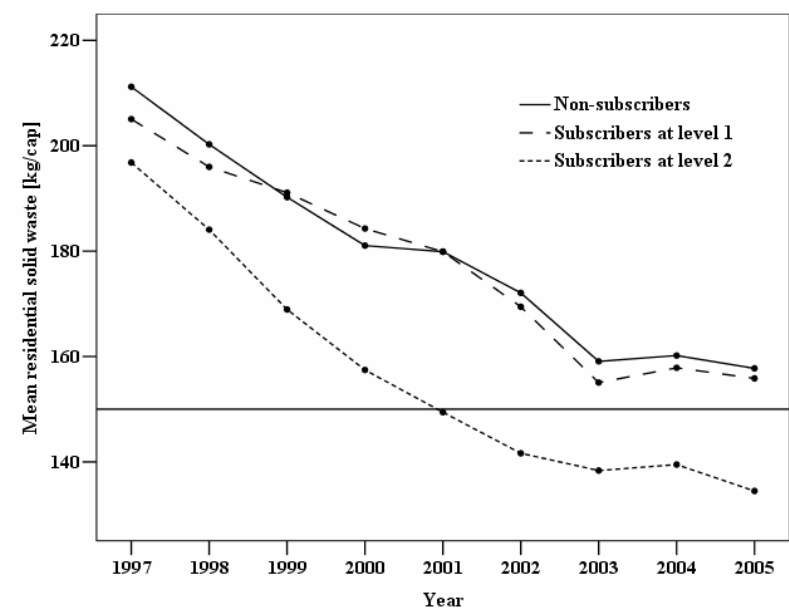

Legend: lines correspond to group averages; error bars denote $+/-2$ times standard error. 
Figure 2: Annual percentage changes in residential solid waste

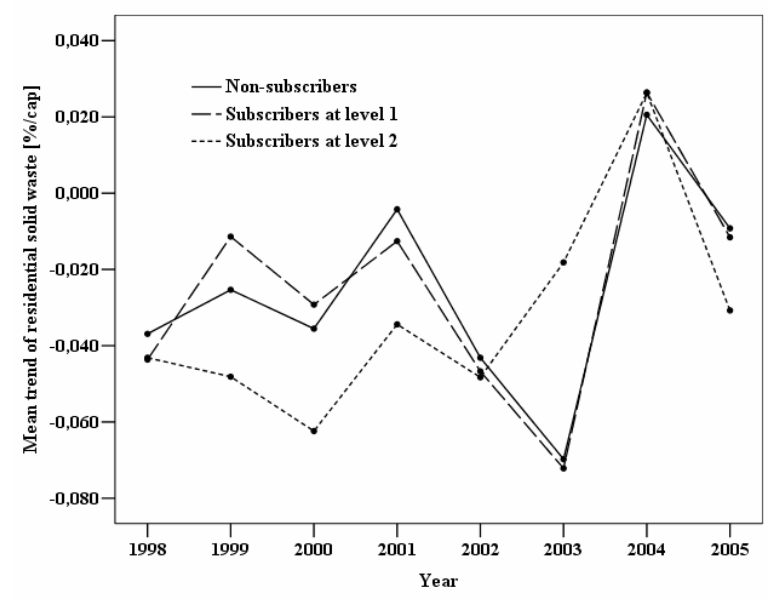

Legend: lines correspond to group averages; reduction $=\left[\mathrm{y}_{\mathrm{i}, \mathrm{t}-1} / \mathrm{y}_{\mathrm{i}, \mathrm{t}}\right]-1$. 
Figure 3: Graphical illustration DiDiD estimator

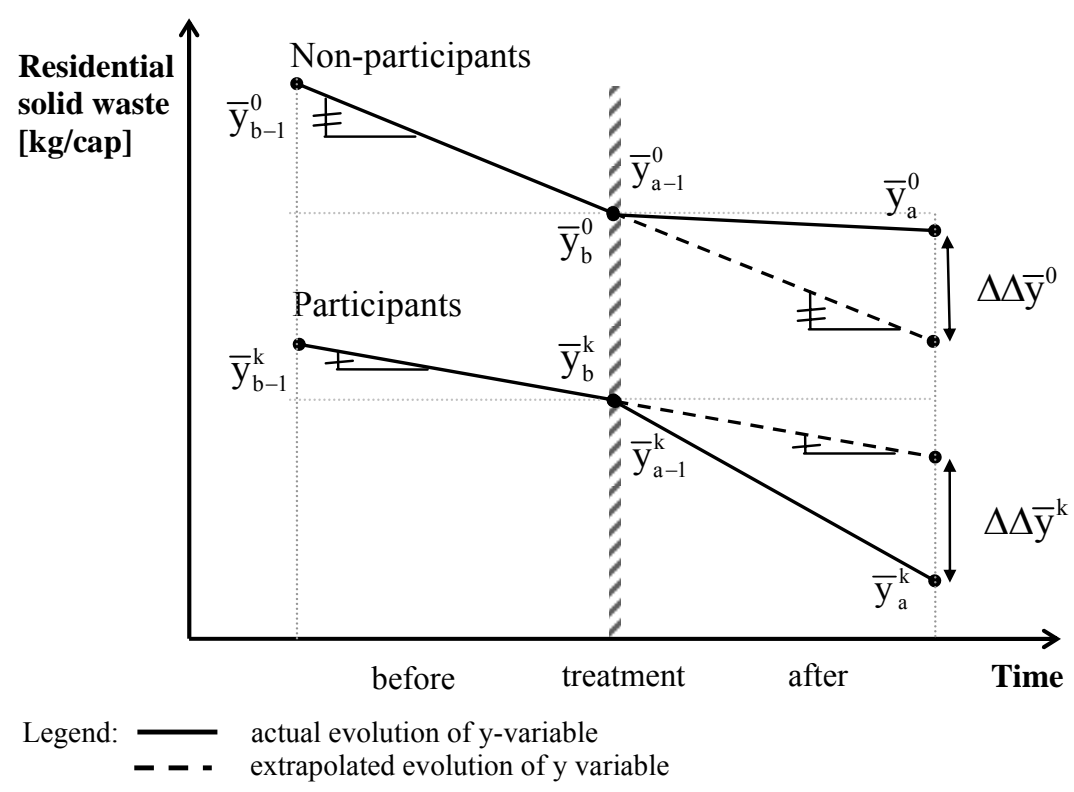


Copyright (c) 2007 @ the author(s). Discussion papers are in draft form. This discussion paper is distributed for purposes of comment and discussion only. It may not be reproduced without permission of the copyright holder. Copies of working papers are available from the author. 